\title{
Autonomy supported, learner-controlled or system- controlled learning in hypermedia environments and the influence of academic self-regulation style
}

Citation for published version (APA):

Gorissen, C., Kester, L., Brand-Gruwel, S., \& Martens, R. (2015). Autonomy supported, learner-controlled or system-controlled learning in hypermedia environments and the influence of academic self-regulation style. Interactive LearnIng Environments, 23(6), 655-669. https://doi.org/10.1080/10494820.2013.788038

DOI:

10.1080/10494820.2013.788038

Document status and date:

Published: 01/01/2015

Document Version:

Peer reviewed version

\section{Document license:}

CC BY-NC-SA

Please check the document version of this publication:

- A submitted manuscript is the version of the article upon submission and before peer-review. There can be important differences between the submitted version and the official published version of record. People interested in the research are advised to contact the author for the final version of the publication, or visit the DOI to the publisher's website.

- The final author version and the galley proof are versions of the publication after peer review.

- The final published version features the final layout of the paper including the volume, issue and page numbers.

Link to publication

\section{General rights}

Copyright and moral rights for the publications made accessible in the public portal are retained by the authors and/or other copyright owners and it is a condition of accessing publications that users recognise and abide by the legal requirements associated with these rights.

- Users may download and print one copy of any publication from the public portal for the purpose of private study or research.

- You may not further distribute the material or use it for any profit-making activity or commercial gain

- You may freely distribute the URL identifying the publication in the public portal.

If the publication is distributed under the terms of Article $25 \mathrm{fa}$ of the Dutch Copyright Act, indicated by the "Taverne" license above, please follow below link for the End User Agreement:

https://www.ou.nl/taverne-agreement

Take down policy

If you believe that this document breaches copyright please contact us at:

pure-support@ou.nl

providing details and we will investigate your claim.

Downloaded from https://research.ou.nl/ on date: 26 Apr. 2023 


\title{
Autonomy supported, Learner-controlled or System-controlled Learning in Hypermedia
}

\section{Environments and the Influence of Academic Self-regulation Style}

\author{
Chantal J.J. Gorissen ${ }^{1}$, Liesbeth Kester ${ }^{1}$, Saskia Brand-Gruwel ${ }^{1}$, and Rob Martens ${ }^{2}$ \\ ${ }^{1}$ Centre for Learning Sciences and Technologies, Open University of The Netherlands, Heerlen, \\ The Netherlands.
}

${ }^{2}$ Scientific Centre Teachers Research, LOOK, Open University of The Netherlands, Heerlen, the Netherlands

\section{Author Note}

This research was funded by Kennisnet, the knowledge centre for information and communication technologies and education in the Netherlands.

Correspondence concerning this paper should be addressed to Chantal Gorissen, Centre for Learning Sciences and Technologies, Open University of The Netherlands, P.O. Box 2960, 6401 DL Heerlen, The Netherlands. Tel:+31 45576 2582, Fax: +31 45576 2800, Chantal.Gorissen@ou.nl 


\begin{abstract}
This study focuses on learning in three different hypermedia environments that either support autonomous learning, learner-controlled learning or system-controlled learning and explores the mediating role of academic self-regulation style ( ASRS; i.e., a macro level of motivation) on learning. This to gain more insight in the conditions under which learning in hypermedia environments is effective. Sixty-nine grade five students from a primary school answered short essay questions using video material from a hypermedia environment. The effects on task motivation and test performance were measured. It was found that learners in the autonomy supported hypermedia environment reported lower levels of controlled task motivation, compared to the learners in the system-controlled and learner-controlled hypermedia environments. But there were no effects of hypermedia environment on autonomous task motivation or the reported need fulfilment for autonomy. Furthermore, learners in the learnercontrolled hypermedia environment scored lower on a delayed, in-depth knowledge test compared to learners in the other two environments. Moreover, learners in the autonomy supported hypermedia environment watched more (unique) videos compared to learners in the system-controlled and the learner-controlled hypermedia environments. As for the role of learners' ASRS, we found no interaction with the type of hypermedia environment on task motivation or performance. Learners' ASRS did, however, affect the learners motivation for the task. And, when presented with advice (as in the autonomy supported hypermedia environment) learners with an autonomous self-regulation style followed more advice, compared to learners with a more controlled self-regulation style.
\end{abstract}


Keywords: hypermedia, autonomy, learner control, system control, self-determination theory, academic self-regulation style. 


\section{Autonomy supported, Learner-controlled or System-controlled Learning in Hypermedia}

\section{Environments and the Influence of Academic Self-Regulation Style}

In educational practice (from primary schools up to universities) the use of hypermedia learning environments increases (Kennisnet, 2011; Tabbers, Martens, \& van Merriënboer, 2004). These hypermedia learning environments are characterized by a network-like information structure, and different information presentation formats (e.g., video, animation, pictures, text, sounds). Scheiter and Gerjets (2007) provided an overview of arguments that have been brought forward as to why hypermedia environments might be effective. Hypermedia environments are said to reflect the learners schemata, increase interest and motivation, provide room for adaptation to preferences and cognitive needs, lead to active and constructive information processing, and lead to the acquisition of self-regulatory skills (e.g., Scheiter \& Gerjets, 2007). So, the structure of these environments allows learners to explore the content in different ways and select information in accordance with their personal needs and preferences. Hypermedia environments can offer a high amount of learner control. Thus, the learner is required to be more involved in the study process and more active, whereas in a traditional educational environment, it is easier for a learner to be passive.

\section{Control and Motivation}

In the review of Skinner (1996) it is noted that 'when people perceive that they have a high degree of control, they exert effort, try hard, initiate action, and persist in the face of failure and setbacks' (p. 556). Indeed, important motivational theories, such as Self-Determination Theory (SDT; Deci \& Ryan, 2000; Ryan \& Deci, 2000) argue that humans have an innate need for control, by SDT referred to as autonomy. SDT states that the need for autonomy is one of the three basic psychological needs (i.e., autonomy, competence, and relatedness) people have in 
order to thrive in life (Deci \& Ryan, 2000; Ryan \& Deci, 2000). The need for autonomy means that people need to feel a sense of full volition and conscious choice regarding their activities and goals. The fulfilment of these needs will determine what type of motivation people have when they perform an activity. Note that SDT defines motivation as the reason or why of behaviour, which is found to also have effects on how learners deal with their learning environment (Deci \& Ryan, 2000; Ryan \& Deci, 2000).

Learner control may foster learners' sense of autonomy, but this is not necessarily the case, as not all types of control may be perceived as contributing to learners self-determination. In other words, when learners are provided with control over things they do not want, this may not contribute to their sense of autonomy. To be autonomous, may be to have control on a higher level than simply control over a surface features of a task. Providing control without forcing learners to take control, may support autonomous feelings (Deci \& Ryan, 1985).

\section{Control and Learning}

Although learner control may positively affect feelings of autonomy and thus motivation, from a performance perspective, learner control in hypermedia environments often leads to disappointing results (Scheiter \& Gerjets, 2007; Skinner, 1996; Schwartz, 2000; Kirschner, Sweller \& Clark, 2006). The freedom to choose between a large amount of options may overload, distract or even disorientate learners (Chen, Fan, \& Macredie, 2006; Gall \& Hannafin 1994; Gulikers, Bastiaens, \& Martens, 2005; Kay, 2001; Scheiter \& Gerjets, 2007). Studies have also shown that especially novices or learners with low prior knowledge and self-regulatory skills are likely to select suboptimal options or information (Kalyuga, Ayres, Chandler, \& Sweller, 2003; Chen, Fan \& Macredie, 2006; Scheiter \& Gerjets, 2007), which in turn is not effective for learning. 
According to Skinner (1996), an explanation for these results might be that there is little consensus about what types of control are beneficial or harmful for learning as well as what the interactions are with certain learner characteristics (e.g., self-regulation style, task motivation, prior knowledge) and situational characteristics (e.g., control over content, pacing or task order). Thus, taking learner characteristics into account, next to the situational characteristics, may offer more insight in how to counteract the negative effects of learner control on learning. This insight is important since to date there is no well-established consensus on how to implement learner control in such a way that it may eventually contribute to learning. This study zooms in on the effects of one of those learner characteristics, namely self-regulation style on task motivation and learning in hypermedia environments.

\section{Control and Self-Regulation Style}

In SDT, self-regulation styles are differentiated in terms of the degree to which persons show autonomous or self-determined (versus controlled) functioning. The more autonomous or self determined, the more a person acts according to one's own free will. This, in contrast to controlled functioning, where there is always a pressure that leads to the executed behaviour. These style differences are most often researched at a macro level (e.g., Ryan \& Connell, 1989) (i.e., Academic Self-Regulation Style e.g., attitude towards school and learning), however some studies measure these motivational regulation styles at a more micro or situational level (i.e., task motivation) (e.g., Boekaerts, van Nuland, \& Martens, 2010). The academic self-regulation style that learners exhibit at a macro level may not automatically transfer to task motivation on a micro level. For example, even when learners are highly autonomously motivated for their studies this does not mean that they will like and/or value every single learning task or situation. The regulatory style, on a macro or micro level, learners have is considered to be an individual 
difference, although these are not "trait" concepts, because they are not general or stable. But they are also not "state" concepts, because they are more stable than typical states which tend to fluctuate more easily over time and in different places (Ryan \& Connell, 1989; Ryan \& Deci, 2000).

Numerous studies that are theoretically founded on SDT (e.g., Grolnick \& Ryan, 1987; Martens, Gulikers, \& Bastiaens, 2004; Vansteenkiste, Simons, Lens, Soenens, \& Matos, 2005) concluded that the different types of regulation styles lead to different types of study behaviour and, consequently, to different learning results. Some studies have, for example, indicated that when learners study from an intrinsic, autonomous regulation style (i.e., the activity is initiated for its own sake because it is satisfying in itself, or because the activity is of personal importance to the learner), they show more deep level approaches to learning, resulting in in-depth knowledge (Grolnick \& Ryan, 1987; Vansteenkiste, Lens, \& Deci, 2006; Wolters \& Pintrich, 1998). In addition, Martens, Gulikers, and Bastiaens (2004) found that in electronic learning environments, learners with a high intrinsic, autonomous regulation style are more curious and explorative. In contrast, when people study from an extrinsic, controlled regulation style (i.e., the activity is initiated as a result of internal or external pressure and not by one's own free will), they rely more on techniques such as rote learning and memorization, resulting in more factual knowledge (cf. Vansteenkiste, Simons, Lens, Soenens, \& Matos, 2005). Apparently, an autonomous regulation style as compared to controlled regulation style leads to better, deeper learning (e.g., in-depth understanding vs. memorized facts).

\section{The Current Study}

The aim of the current study is to gain more insight in the conditions under which learning in hypermedia environments is effective. In this study a differentiation is made between 
different types of control that is provided to the learners in a hypermedia environment. We aim to investigate the effects of autonomy supported learning, learner-controlled learning or systemcontrolled learning on students learning results and motivation for the tasks. Also, the mediating role of academic self-regulation style ( ASRS; i.e., a macro level of motivation) on learning is explored.

The differentiation between the types of control offered in the different hypermedia environments is made by differences in the options learners have in the hypermedia environments. System-controlled learning is supported by providing learners with a fixed standardized list of materials to be used for each of the tasks. Learner-controlled learning is supported by giving learners full control over which and how much material they select from a database, for task completion. In turn, the presentation of the control options in autonomy supported learning is identical to that in learner-controlled learning except for one important difference, the learners were given advice on what content to select given a particular task.

The provision of choice is often considered to be the way to support feelings of autonomy (Reeve, Nix, \& Hamm, 2003). However, the difference between autonomy supportive choices and other choices lies in the way they are presented to the learners and in the meaning the options have to them (Katz \& Assor, 2007). As Ullmann-Margalit and Morgenbesser (1997) stated, there is a difference between consciously choosing and randomly picking an option, and the effect it has on need satisfaction for autonomy. In order for choices to be autonomy supportive, they should not be forced upon the learner, but rather be offered as advice, which the learner can decide not to take. Therefore, autonomy supported learning is in this study supported by giving learners the option not to choose. This may sound as a paradox but it means that 
learners can choose their own leaning materials or when they are unable or unwilling to do so, they can simply choose to follow the advised material.

We hypothesize that learners who learn in an environment that supports autonomous learning will more often show autonomous task motivation (i.e., regulation style on a micro level), as compared to learners who learn in an environment that supports learner-controlled learning or system-controlled learning, because of a greater sense of need fulfilment for autonomy (hypothesis 1). Furthermore, while learners in each hypermedia environment should be able to achieve similar performance on factual knowledge, we expect that learners in the autonomy supported environment score higher on in-depth knowledge than learners who learn in the other environments because 1) an autonomous task motivation leads to deep learning and 2) the advice given in the autonomy supported learning environment helps learners choose the most suitable learning material (hypothesis 2).

Furthermore, it is important to consider the self-regulation style that a learner holds for learning and school in general, and the degree to which they want to be 'autonomous' in their learning (Academic Self-Regulation Style: ASRS; Ryan \& Connell, 1989). Since, feelings of autonomy are likely to be strong when people perceive the task they are performing as closely connected to their own value, goals, and interests that make up the core of their authentic self and identity (Katz \& Assor, 2007). As a consequence, the task and a learner's self-regulation style might best be aligned. Therefore, we explore the effects of ASRS in combination with the different types of hypermedia environment on task motivation and performance.

Moreover, this study focuses on students around the age of 10. Since, most studies on leaner control, autonomy and hypermedia learning involve adult participants, there is little information on the way in which children deal with these issues (Grennan-Paxton \& Roeder 
John, 1995). However, studies on children's choice strategies and decision making skills, show that children tend to use the same strategies as adults when confronted with a tasks of age appropriate complexity level (Bereby-Meyer, Assor \& Katz, 2003; Grennan-Paxton \& Roeder John, 1995). When confronted with choices that are to complex, children rely on decision strategies that are similar to those of adults who are confronted with too complex choices (Bereby-Meyer, Assor \& Katz, 2003; Grennan-Paxton \& Roeder John, 1995).

\section{Method}

\section{Participants}

Sixty-nine grade five students ( 37 males and 32 females; mean age $=10.6$ years, $S D=$ .7), from a primary school in the Netherlands participated in this study, which took place during regular school hours and within the regular class setting.

\section{Materials}

Learning environment. A hypermedia learning environment was designed and built for this study. This environment contained all the essay questions, tests and questionnaires that were used in this study. Video material from an existing environment, called ED*IT (Nederlands Instituut voor Beeld en Geluid [Dutch Institute for Sound and Vision ], NTR, \& Kennisnet, 2009), was integrated by means of hyperlinks into the hypermedia learning environment. The activities, for example each video that was watched, of the learners in the learning environment were logged.

Essay questions. The domain for this study, was geography, with the specific topics volcanoes and earthquakes. All learners answered eight short essay questions about these topics. Each essay question focussed on a sub-topic, for example, 'How does a volcano eruption occur?' and 'How can you measure and predict a volcano eruption?'. The instruction for the essay 
questions was to write a short essay about the selected question, and to use the presented video material to search for information on the topics.

Performance measures. The learners' learning outcomes were measured by means of two different performance measures. The Factual Knowledge Test measured the amount and quality of their factual knowledge and consisted of 67 true/false/no answer statements. The InDepth Knowledge Test consisted of 21 open questions that measured the amount of understanding of the subject by having learners explain relationships between concepts.

Academic self-regulation style (ASRS). A Dutch translation of the Academic SelfRegulation Questionnaire (ASRQ; original from Ryan \& Connell, 1989) was used to measure the learners' ASRS. This questionnaire concerns the reasons why children do their school work and consisted of 32 items which were rated by the learners on a 4-point Likert scale. The questionnaire consists of 2 scales, Controlled regulation and Autonomous regulation. Reliability analysis for showed a Cronbach's $\alpha$ of .75 and .91 respectively.

Task motivation and need fulfilment for completing the essay questions. The type of motivation the learners had for completing the essay questions was measured by a questionnaire in Dutch based on the Intrinsic Motivation Inventory from Ryan (1982). This questionnaire was combined with the Basic Psychological Needs scale (Ilardi, Leone, Kasser, \& Ryan, 1993; Kasser, Davey, \& Ryan, 1992), which measured the extent to which the basic psychological needs (as proposed by SDT; autonomy, competence, and relatedness) were satisfied. The questionnaire consisted of 37 items (i.e., after items were deleted due to negative item-total correlations) which learners rated on a 7-point Likert scale. Reliability analyses on the five scales showed respectively, Cronbach's $\alpha=.82$ for the Competence Need Scale, Cronbach's $\alpha=.51$ for the Relatedness Need Scale, Cronbach's $\alpha=.63$ for the Autonomy Need Scale, Cronbach's $\alpha$ 
$=.74$ for the Controlled Regulation scale, and Cronbach's $\alpha=.92$ for the Autonomous Regulation scale.

\section{Design and Procedure}

The set-up of this study was a quasi-experimental between-subjects design, with three conditions (hypermedia environment; autonomy supported, learner-controlled, systemcontrolled) with the predictor Academic Self-regulation Style (autonomous, controlled). All conditions involved learners working individually for approximately 3 hours with a hypermedia environment on a computer. Learners worked on this in blocks of 45 minutes spread across 2 weeks. Before they started working in a hypermedia environment, they were first asked to fill out the Academic Self-Regulation Questionnaire and some general information questions (e.g. age, sex and class). Then they worked on the essay questions at their own pace during the 45 -minute blocks over the two weeks they participated in this study.

All participants received the same short essay questions, but they got different instructions. The hypermedia environments differed in the type of control learners had over the learning material. In the system-controlled hypermedia environment, learners worked in a standardized way. The essay questions were offered to the learners in a fixed order and learners were offered a small number of videos (1-7) to watch for each essay question.

In the learner-controlled hypermedia environment, learners were given a database containing all videos. The learners had the freedom to choose anyone of them for each essay question, no structure or advice was provided. The order in which the essay questions were presented was the same as in the system-controlled learning condition, but the learners were free to choose the order in which they worked on them. 
In the autonomy supported hypermedia environment, learners were free to choose their own videos (cf. learner-controlled hypermedia environment), but could also choose for each separate essay question to follow the standardized procedure (cf. the system-controlled hypermedia environment), and, thus, they could also create a mix of the two. Per essay question, a small number of videos was highlighted in the video database which was identical to the database in the learner-controlled hypermedia environment and the highlighted videos corresponded to the presented videos in the system-controlled hypermedia environment. In the instruction, it was explained that the highlighted videos were advised for a certain task, but that the learners were not required to follow this advice and were free to select any other materials from the database they wanted. The order in which the tasks were presented was also the same as in the other two conditions, but as in the learner control condition they were free to choose the order in which they worked on the tasks.

After the learners felt they had completed the tasks, they were given the Intrinsic Motivation Inventory and the Basic Psychological Needs scale. Then, the learning outcomes were measured by having the learners take the Factual Knowledge Test and the In-Depth Knowledge Test. These two performance measure tests were repeated 3 months later.

\section{Scoring and Analysis}

Calculating the proportion of advice followed. By dividing the number of advised videos watched by the number of unique videos watched, we calculated the proportion of advice followed.

Scoring the performance tests. The Factual Knowledge Test (67 true/false/no answer statements) was scored by providing 1 point for each correct answer, -1 point for each false answer, and 0 points for the no answer option. The In-Depth Knowledge Test (21 open 
questions) was scored by awarding 1 point for each correct idea unit. An example of a correct idea unit is 'when magma comes out of a volcano it becomes lava' or 'a volcano eruption can be predicted by means of a seismograph'.

ASRS- RAI. Using the scales of the ASRQ, the Relative Autonomy Index (RAI) was calculated, according to the method described by Grolnick and Ryan (1989). A high RAI score indicates a high autonomous regulatory style and a low RAI score indicates a low autonomous regulatory style.

Analysis. The data were analyzed using SPSS, a significance level of .05 was used for all tests. Multiple regression analyses were used to analyze the effects of our independent variables (i.e., ASRS and hypermedia environment) on the dependent variables (i.e., task motivation, need fulfilment and performance). Because there were three hypermedia environments, we had to recode them into two dummy variables, for which we used the autonomy supported hypermedia environment as a baseline (Field, 2009). An interaction term was created by multiplying the hypermedia environment type with the ASRS-RAI score.

Missing values were coded as missing values, $5.80 \%$ of the scores for Motivation (Intrinsic Motivation Inventory) and need fulfilment (Basic Psychological Needs scale) for completing the essay questions were missing as well as $5.80 \%$ of the scores for the immediate In-depth Knowledge test. Where appropriately, variables were controlled for violations of the statistical assumptions of normality, outliers, and co linearity.

\section{Results}

The means and standard deviations of the dependent variables included in this section per hypermedia environment are included in Table 1.

***Insert Table 1 about here*** 


\section{Task Motivation}

Intrinsic Motivation Inventory. We investigated the effects of Hypermedia Environment, ASRS and the interaction between the ASRS and Hypermedia Environment on the task motivation of the learners. First, a model including the interaction between these variables was investigated. For the controlled task motivation the ANOVA for the model with the predictors Interact, Hypermedia Environment and ASRS was significant $F(4,60)=4.78, R^{2}=.24$, $p=.00$, which means that this model is a good predictor of controlled task motivation. The interact was not significant $(B=.13, S E B=.09, \beta=.45, p=.15)$. For the autonomous task motivation, the ANOVA for the same model showed a trend, $F(4,60)=2.13, R^{2}=.12, p=.09$. Nevertheless, the interact was not significant $(B=.05, S E B=.10, \beta=.17, p=.60)$.

In a next step, both for controlled task motivation and autonomous task motivation, the interact was removed from the analyses to further study the main effects of Hypermedia Environment and ASRS on task motivation. With regard to controlled task motivation, the ANOVA for the model without the predictor Interact was found to be significant $F(3,61)=5.56$, $R^{2}=.22, p=.00$. In accordance with hypothesis 1 , the analysis showed a significant main effect for Hypermedia Environment on the Controlled Regulation Scale. Learners in the system-controlled and learner-controlled hypermedia environments reported higher levels of controlled task motivation, compared to the learners in the autonomy supported hypermedia environment $(B=.61, S E B=.30, \beta=.27, p=.05$ and $B=.74, S E B=.32, \beta=.31, p=.02$, respectively). Furthermore, the analysis also showed a significant main effect for ASRS on the Controlled Regulation scale. Learners with a high ASRS-RAI score reported lower levels of controlled task motivation $(B=$ .19$, SE $B=.07, \beta=-.33, p=.01)$.

For autonomous task motivation, the ANOVA for the model without the predictor 
Interact was also found to be significant $F(3,61)=2.78, R^{2}=.12, p=.05$. However, in contrast to hypothesis 1, no main effects of Hypermedia Environment on the Autonomous Regulation Scale were found for the system-controlled hypermedia environment as compared to the autonomy supported hypermedia environment $(B=.04, S E B=.35, \beta=.02, p=.9)$ or for the learner-controlled hypermedia environment as compared to the autonomy supportive hypermedia environment $(B=-$ $.02, S E B=.37, \beta=-.01, p=.96)$. The analysis showed a significant main effect for ASRS on the Autonomous Regulation scale. Learners with a high ASRS-RAI score reported higher levels of autonomous task motivation $(B=.22, S E B=.08, \beta=.34, p=.01)$.

Basic Psychological Needs scale. We investigated the main effects of Hypermedia Environment and ASRS on the satisfaction of the basic psychological needs (autonomy, competence, and relatedness). For the Autonomy Need Scale the ANOVA for the model with predictors Hypermedia Environment and ASRS was not significant $F(3,61)=2.66, R^{2}=.12$, $p=.06$. In contrast to hypothesis 1 , learners in the different hypermedia environments and with different ASRS did not report a different level of experienced autonomy.

Furthermore, for the Relatedness Need Scale and the Competence Need Scale the ANOVA for the model (with predictors Hypermedia Environment and ASRS) was also not significant, $F(3,61)=2.34, R^{2}=.10, p=.08$. and $F(3,61)=.86, R^{2}=.04, p=.47$ respectively. So, also for the other two basic psychological needs, learners did not report differences in their level of need satisfaction.

\section{Performance}

To investigate the effects of Hypermedia Environment, ASRS, and interaction of ASRS and Hypermedia Environment on the performance scores of the learners, the model including the interaction between these variables was first investigated. For the immediate and delayed Factual 
Knowledge Test the ANOVA for the model with predictors Interact, Hypermedia Environment and ASRS was not significant $F(4,64)=.35, R^{2}=.02, p=.84$ and $F(4,64)=.38, R^{2}=.02, p=.82$ respectively. For the immediate In-Depth Knowledge Test the ANOVA for the same model was also not significant $F(4,64)=1.17, R^{2}=.07, p=.33$. For the delayed In-Depth Knowledge Test, however, the ANOVA for the model was significant $F(4,64)=2.77, R^{2}=.15, p=.03$. Nevertheless, the interact was not significant $(B=-.42, S E B=.37, \beta=-.39, p=.26)$.

In a next step we removed the interact, to further examine the main effects of Hypermedia environment and ASRS on the delayed In-Depth Knowledge Test. For the delayed In-Depth Knowledge Test, the ANOVA for the model without the predictor Interact was found to be significant $F(3,65)=3.25, R^{2}=.13, p=.03$. The analysis showed a significant main effect for Hypermedia Environment on delayed In-Depth Knowledge Test performance. Learners in the learner-controlled hypermedia environment scored significantly lower on the delayed In-Depth Knowledge Test, compared to the learners in the autonomy supported hypermedia environment $(B=-3.68, S E B=1.31, \beta=-.40, p=.01)$. No differences were found between the system-controlled hypermedia environment and the autonomy supported hypermedia environment $(B=-.91, S E B=1.27, \beta=-.10, p=.48)$. Furthermore, no main effect of ASRS on the delayed In-Depth Knowledge Test was found $(B=.01, S E B=.29, \beta=.00, p=.98)$.

\section{Learner actions}

To investigate the effects of Hypermedia Environment and ASRS on the number of videos watched and the number of unique videos watched by the learners, the interaction between these variables was first investigated. For the total number of videos watched, the ANOVA for the model including the predictors Interact, Hypermedia Environment and ASRS was significant $F(4,64)=3.70, R^{2}=.19, p=.01$. However, the interact was not significant $(B=.05$, 
$S E B=1.16, \beta=.01, p=.97)$, therefore the interact was removed from the analysis to further study the main effects.

The ANOVA for the model without the predictor Interact was also found to be significant $F(3,65)=5.00, R^{2}=.19, p=.00$. Learners in the system-controlled and learner-controlled hypermedia environments watched less video's compared to the learners in the autonomy supported hypermedia environment $(B=-7.77, S E B=3.95, \beta=-.26, p=.05$ and $B=-15.53, S E$ $B=4.08, \beta=-.53, p=.00$, respectively). No main effect was found for ASRS on the total number of videos watched by the learners $(B=-.51, S E B=.90, \beta=-.07, p=.58)$.

For the number of unique videos watched, the ANOVA for the model including the predictors Interact, Hypermedia Environment and ASRS was significant $F(4,64)=3.77, R^{2}=.19$, $p=.01$. However, the interact was not significant $(B=-.43, S E B=.70, \beta=-.20, p=.55)$, therefore the interact was removed from the analysis to further study the main effects.

The ANOVA for the model without the predictor Interact was also found to be significant $F(3,65)=4.95, R^{2}=.19, p=.00$. The analysis showed a significant main effect for Hypermedia Environment on the number of unique videos watched. Learners in the system-controlled and learner-controlled hypermedia environments watched significantly less unique video's compared to the learners in the autonomy supported hypermedia environment $(B=-6.74, S E B=2.38, \beta=-.37$, $p=.01$ and $B=-8.82, S E B=2.46, \beta=-.49, p=.00$, respectively). No main effect was found for ASRS on the number of unique videos watched by the learners $(B=-.32, S E B=.55, \beta=-.07, p=.57)$.

Advice. Learners in the autonomy supported hypermedia environment had received advice about which videos they could use for a specific task. A simple regression analysis showed that the ASRS had a significant effect on the proportion of advice that was followed $F(1$, 
$20)=5.86, R^{2}=.23, B=.05, S E B=.02, \beta=.48, p=.03$. Learners with a high ASRS-RAI-score tended to follow more advice compared to the learners with a low ASRS-RAI-score.

\section{Discussion}

In this study, we examined learners' learning in three different hypermedia environments that either supported autonomous learning, learner-controlled learning or system-controlled learning and we explored the mediating role of ASRS on this learning. The results of this study partially confirm hypothesis 1 , in that we found a main effect of hypermedia environment on task motivation indicating that learners in the autonomy supported hypermedia environment reported lower levels of controlled task motivation, compared to the learners in the system-controlled and learner-controlled hypermedia environments. However, we found no main effects of hypermedia environment on autonomous task motivation or the reported need fulfilment for autonomy.

Secondly, the results also partially confirmed hypothesis 2 . Analysis showed a main effect of hypermedia environment on test performance indicating that learners in the learnercontrolled hypermedia environment scored significantly lower on delayed, in-depth knowledge, compared to the learners in the autonomy supported hypermedia environment. However, no differences in performance were found between learners in the system-controlled hypermedia environment and the autonomy supported hypermedia environment on delayed in-depth knowledge. In addition, the hypermedia environments did not affect performance on immediate in-depth knowledge. Moreover as expected, no differences were found between learners in the three hypermedia environments on immediate and delayed factual knowledge performance.

How can these results be explained? A possible explanation for the lack of effect of the hypermedia environment on autonomous task motivation and the need fulfilment for autonomy (hypothesis 1) may be that the learners may not fully have perceived the control. We question if 
it is possible to influence learners' sense of autonomy by providing control at a task level within a school setting. In line with van Nuland, Taris, Boekaerts, \& Martens, (2011) it can be argued that in a school setting were most activities are mandatory by default, a school task may be experienced as just another set of mandatory activities (cf. Martens, de Brabander, Rozendaal, Boekaerts, \& van der Leeden, 2010). The degree to which learners have the possibility to actually exert control during the task may not be relevant to them, as the task itself is mandatory. When learners do not perceive the control, it is likely that their need fulfilment for autonomy is not influenced by it. Moreover according to Kohn (2010), it may not be possible to motivate anyone, except yourself. He claims that you can make learners do something (by using rewards and/or punishments), but you cannot make them want to do those things. The only thing 'what teachers clearly have the ability to do with respect to students' motivation is kill it.' (Kohn 2010, p.1 ). This statement seems to be in line with our findings on task motivation. While the level of autonomous task motivation (i.e., 'wanting' to do the task) was not increased in learners, the level of controlled task motivation (i.e., only doing the task because it is mandatory) was decreased by providing autonomy support.

Moreover, we assumed that hypermedia environment has an effect on learner performance (hypothesis 2). We had two reasons for expecting that the type of hypermedia environment would affect in-depth knowledge performance differently. Firstly, we expected that the amount of autonomous task motivation resulting from the hypermedia environments would influence this performance, the higher the autonomous task motivation the deeper the learning. Since no differences in autonomous task motivation were found between learners in the different hypermedia environments this reason does not hold. Secondly, we expected that learners who 
were given advice (i.e., the autonomy supported learning environment) choose the most suitable learning material and hence perform best on in-depth knowledge.

The results concerning user actions show main effects of hypermedia environment on the number of videos watched and the number of unique videos watched. Learners in the autonomy supported hypermedia environment watched more videos in total and more unique videos compared to learners in the system-controlled and the learner-controlled hypermedia environments. This indicates that learners in the autonomy supported hypermedia environment selected richer learning material which could explain the superior performance of these learners on delayed in-depth knowledge but does not explain why this effect does not appear on immediate in-depth knowledge. The differences in mean immediate in-depth knowledge performance are however in the same direction as those of the delayed in-depth performance.

We also explored how ASRS (i.e., regulation style at a macro level) influences a learner's task motivation and performance in the different hypermedia environments. There was no interaction of ASRS with the hypermedia environments on learners' task motivation. Nevertheless, we did find a main effect of ASRS on task motivation indicating that learners with a more autonomous self-regulation style report lower levels of controlled task motivation and higher levels of autonomous task motivation as compared to learners with a more controlled selfregulation style. It seems that the learners' regulation style on a macro level (i.e., ASRS) determined their regulation style on a micro level (i.e., task motivation) regardless of the environment they learned in. No performance differences for ASRS or for the interaction between ASRS and hypermedia environment were found.

Furthermore, for learners in the autonomy supported hypermedia environment who had received advice about which videos they could use for a specific task, the ASRS influenced the 
extent to which they followed the advice. Learners with a more autonomous self-regulation style followed more advice, compared to learners with a more controlled self-regulation style. Based on the academic self-regulation questionnaire, learners with a more autonomous self-regulation style have a more positive attitude towards school and school work than learners with a more controlled self-regulation style. So here, the learners with a more autonomous self-regulation style are the learners who think school and learning are important and/or fun. These 'good' learners may have been the ones who wanted to do the tasks right by following the advice that was offered, and thus getting a 'guarantee' about what was the right thing to do.

\section{Limitations}

One of the limitations of this study is the relatively small sample of participants. Even though the sample was theoretically large enough to perform the analyses used, it may explain the modest effects found. Especially because some of the patterns of the scores are in the expected direction but not significant, for example, the immediate in-depth knowledge performance scores. The small sample may have resulted in type two errors. The fact that the study was performed in an regular school setting, although great for the ecological validity, may have also caused additional noise in the data. Furthermore, the results concerning the Autonomy Need scale of the Basic Psychological Needs Scale need to be interpreted with caution because of the low reliability.

\section{Conclusion}

In conclusion, the results from this study show that providing learners with autonomy support in a hypermedia learning environment has some beneficial effects for learners compared to system-controlled and learner-controlled hypermedia learning environments. However, it proved difficult to manipulate learners' motivation on a task level in a positive way, despite a 
decrease of negative motivation. For future research and task design we might want to focus less on attempts to raise (intrinsic) motivation, but more to rely on preserving the motivation that is already present in the learners and on providing the possibility to further develop this motivation. As expected, learner characteristics appear to influence the way in which learners deal with a hypermedia environment, especially when it comes to dealing with advice. So, to further investigate the provision of autonomy support to learners in the form of advice, we need to broaden our understanding of why specific learners with specific characteristics deal with instruction in a certain way. 


\section{References}

Boekaerts, M., Van Nuland, H. J. C., \& Martens, R. L. (2010). Perspectives on motivation: What mechanisms energise students' behaviour in the classroom. In J. Kleine Staarman, K. Littleton, \& C. Wood (Eds.), Handbook of Educational Psychology (pp. 535-569). Bingley, UK: Emerald.

Bereby-Meyer, Y., Assor, A., \& Katz, I. (2003) Children's choice strategies: the effects of age and task demands. Cognitive development, 19, 127-146.

Deci, E. L., \& Ryan, R. M. (1985). Intrinsic motivation and self-determination in human behavior. New York: Plenum.

Deci, E. L., \& Ryan, R. M. (2000). The 'What' and 'Why' of goal pursuits: Human needs and the self-determination of behaviour. Psychological Inquiry, 11, 227-268.

Chen, S. Y., Fan, J.-P., \& Macredie, R. D. (2006). Navigation in hypermedia learning systems: Experts vs. novices. Computers in Human Behaviour, 22, 251-266.

Field, A. (2009). Discovering Statistics using SPSS. London: Sage

Gall, J. E., \& Hannafin, M. J. (1994). A framework for the study of hypertext. Instructional Science, 22, 207-232.

Grennan-Paxton, J. \& Roeder John, D. (1995). Are young children adaptive decision makers? A study of age differences in information search behaviour. Journal of Consumer Research, $21,567-580$.

Grolnick, W. S.,\& Ryan, R. M. (1987). Autonomy in children's learning: An Experimental and individual difference investigation. Journal of Personality and Social Psychology, 52, 890-898. 
Grolnick, W. S., \& Ryan, R. M. (1989). Parent style associated with children's self-regulation and competence in school. Journal of Educational Psychology, 81, 143-154.

Gulikers, J., Bastiaens, Th., \& Martens, R. (2005). The Surplus Value of an Authentic Learning Environment. Computers in Human Behaviour, 21, 509-521.

Ilardi, B. C., Leone, D., Kasser, R., \& Ryan, R. M. (1993). Employee and supervisor ratings of motivation: Main effects and discrepancies associated with job satisfaction and adjustment in a factory setting. Journal of Applied Social Psychology, 23, 1789-1805.

Kalyuga, S., Ayres, P., Chandler, P., \& Sweller, J. (2003). The expertise reversal effect. Educational Psychologist, 38, 23-31.

Kasser, T., Davey, J., \& Ryan, R. M. (1992). Motivation, dependability, and employeesupervisor discrepancies in psychiatric vocational rehabilitation settings. Rehabilitation Psychology, 37, 175-187.

Katz, K.,\& Asor, A. (2007) When Choice Motivates and When It Does Not. Educational Psychology Review, 19, 429-442.

Kay, J. (2001). Learner control. User Modeling and User-Adapted Interaction, 11, 111-127.

Kennisnet (2011). Vier in Balans Monitor 2011. Ict in het onderwijs: de stand van zaken [Four in Balance Monitor 2011. ICT in education: the state of affairs]. Zoetermeer: Kennisnet

Kirschner, P. A., Sweller, J., \& Clark, R. E. (2006). Why minimal guidance during instruction does not work: An analysis of the failure of constructivist, discovery, problem-based, experiential, and inquiry-based teaching. Educational Psychologist, 41, 75-86.

Kohn, A. (2010). How to create Nonreaders: Reflections on Motivaton, Learning, and Sharing Power. English Journal, 100 (1), 16-22. 
Martens, R.L., Gulikers, J., \& Bastiaens, T. (2004). The impact of intrinsic motivation on elearning in authentic computer tasks. Journal of Computer Assisted learning, 20, 368376.

Martens, R ., de Brabander, C., Rozendaal, J., Boekaerts, M., \& van der Leeden, R. (2010). Inducing mind sets in self-regulated learning with motivational information. Educational Studies, 36, 311-329.

Nederlands Instituut voor Beeld en Geluid [Dutch Institute for Sound and Vision ], NTR, \& Kennisnet (2009). ED*IT [Educational videos]. Retrieved from http://www.edit-basis.nu/

Reeve, J., Nix, G., \& Hamm, D. (2003). Testing models of the experience of self-determination in intrinsic motivation and the conundrum of choice. Journal of Educational Psychology, 95, 375-392.

Ryan, R. M. (1982). Control and information in the intrapersonal sphere: An extension of cognitive evaluation theory. Journal of Personality and Social Psychology, 43, 450461.

Ryan, R. M., \& Connell, J. P. (1989). Perceived locus of causality and internalization: Examining reasons for acting in two domains. Journal of Personality and Social Psychology, 57, 749-761.

Ryan, R. M., \& Deci, E. L. (2000). Self-determination theory and the facilitation of intrinsic motivation, social development, and well being. American Psychologist, 55, 68-78.

Scheiter, K., \& Gerjets, P. (2007). Learner control in hypermedia environments. Educational Psychology Review, 19, 285- 307.

Schwartz, B. (2000). Self-Determination: the tyranny of freedom. American Psychologist, 55, 79- 88 . 
Skinner, E.A. (1996). A Guide to Constructs of Control. Journal of Personality and Social Psychology, 71, 549- 570.

Tabbers, H., Martens, R. \& van Merriënboer, J. (2004). Multimedia instructions and cognitive load theory: Effects of modality and cueing. British Journal of Educational Psychology, $74,71-81$.

Ullmann-Margalit, E., \& Morgenbesser, S. (1997). Picking and choosing. Social Research, 44, $757-785$.

Van Nuland, H, Taris, T., Boekaerts, M., \& Martens, R. (2011). Testing the hierarchical SDT model: the case of performance-oriented classrooms. European Journal of Psychology of Education. Advance online publication. DOI 10.1007/s10212-011-0089-y

Vansteenkiste, M., Lens, W., \& Deci, E. L. (2006). Intrinsic Versus Extrinsic Goal Contents in Self-Determination Theory: Another Look at the Quality of Academic Motivation. Educational Psychologist, 41, 19-31.

Vansteenkiste, M., Simons, J., Lens, W., Soenens, B., \& Matos, L. (2005). Examining the impact of extrinsic versus intrinsic goal framing and internally controlling versus autonomysupportive communication style upon early adolescents' academic achievement. Child Development, 76, 483-501.

Wolters, C. A., \& Pintrich, P. R. (1998). Contextual differences in student motivation and selfregulated learning in mathematics, English and social studies classrooms. Instructional Science, 26, 27-47. 
Table 1

Means and standard deviations of the dependent variables

\section{Conditions}

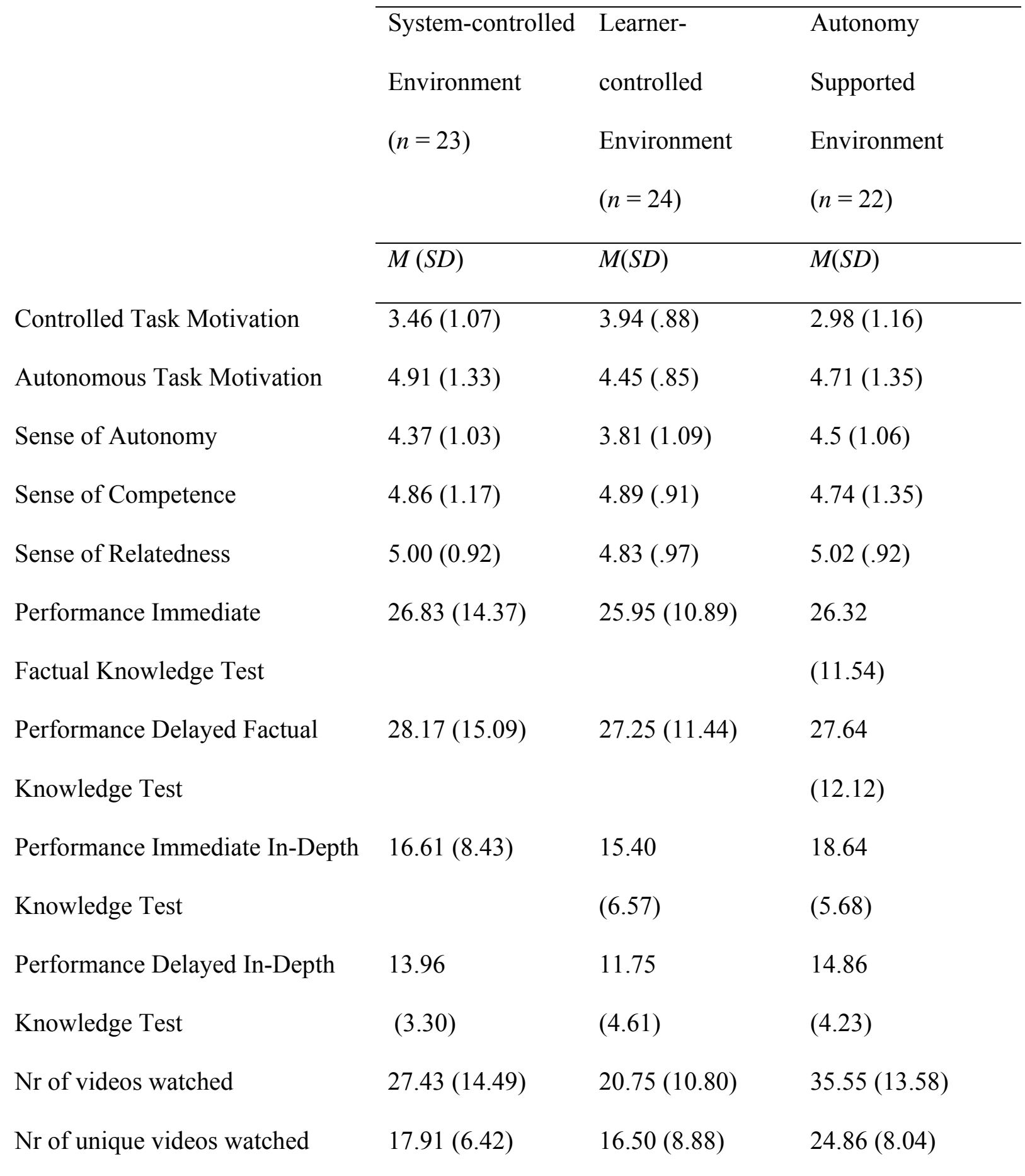


